\title{
Compartment Syndrome after Abdominal Aortic Aneurysm Repair
}

\author{
Tadashi Omoto*, Atsushi Aoki, Kazuto Maruta and Tomoaki Masuda \\ Department of Cardiovascular Surgery, Showa University, Japan
}

Submission: June 26, 2017; Published: July 26, 2017

*Corresponding author: Tadashi Omoto, Department of Cardiovascular Surgery, Showa University Hatanodai 1-5-8, Shinagawa-ku, Tokyo, 1428666, Japan, Tel: +81-3-3784-8588; Fax: +81-3-3784-8307; Email: tomoto@med.showa-u.ac.jp

\begin{abstract}
We report a case of 50-year-old man who presented with acute compartment syndrome of the left lower limb after abdominal aortic aneurysm repair. He had past history of vasospastic angina which was diagnosed by acetylcholine provocation test 7 years before the operation. He had several episodes of lower leg pain, which sustained around 15-30 minutes during rest. Scheduled Y graft replacement was performed with total operative time of 245 minutes and total ischemic time of 111 minutes. He complained of severe pain of his left lower limb just after the operation. Laboratory data showed increased transaminase (aspartate transaminase $363 \mathrm{mg} / \mathrm{dl}$, alanine transaminase $99 \mathrm{mg} / \mathrm{dl}$ ) and creatine kinase $(36273 \mathrm{mg} / \mathrm{dl})$. Contrast computed tomography (CT) demonstrated normal vasculature of the anterior tibial, posterior tibial and peronial arteries, however, significant swelling of the soleus muscle was found (Figure 1). Although infusion of heparin and prostaglandin E1 were started, compartment syndrome had developed and fasciotomy was performed. Discoloration of the toes of the left foot started one week after the operation and deteriorated (Figure 2). Amputation of the second, third and fourth toes was performed 4 months after the operation.
\end{abstract}
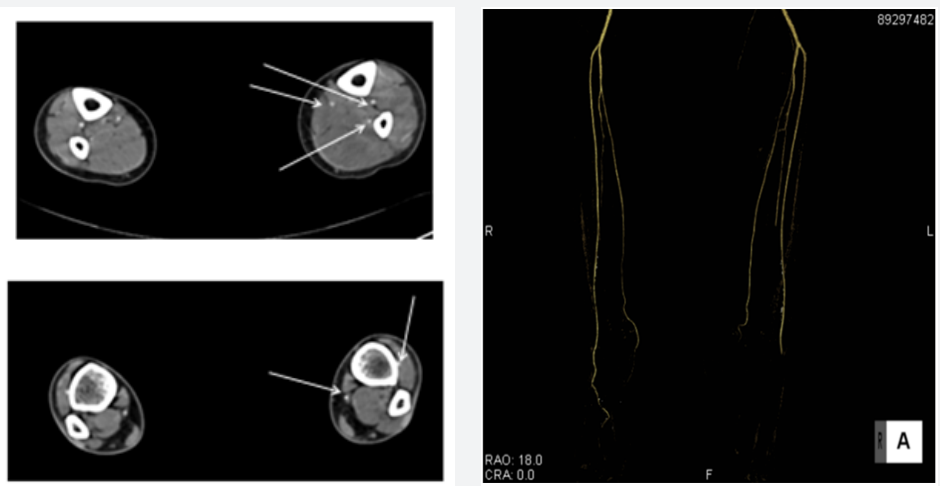

Figure 1: Normal vasculature of the anterior tibial, posterior tibial and peronial arteries (arrows).
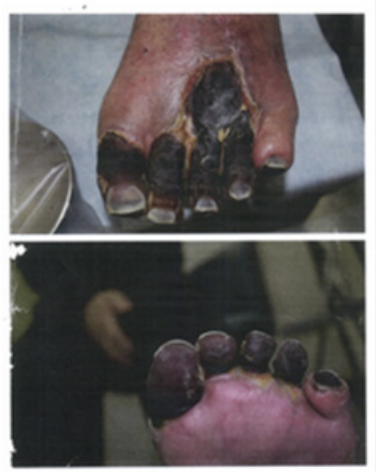

Figure 2: Foot gangrene: 2 months after theoperation.

\section{Case Presentation}

We present a case of a 50-year-old man who underwent Y graft replacement for infra-renal abdominal aortic aneurysm of the maximum diameter of $50 \mathrm{~mm}$. He had past history of vasospastic angina which was diagnosed by acetylcholine provocation test 7 years before the operation, and benidipine had been prescribed. He had several episodes of lower leg pain, which sustained around 15-30 minutes during rest. There was no significant coronary artery stenosis by preoperative coronary computed tomography. He underwent scheduled Y-graft replacement by woven Dacron (Vascular Triplex®, Termo Corporation, Tokyo, Japan). Sevoflurane, popscaine and fentanyl were used for general anethesia. With standard midline, transperitoneal incision, the abdominal aorta was exposed, and graft replacement was started from proximal anastomosis, then anastomosis of the right common iliac artery, left common iliac artery, and inferior mesenteric artery, were followed. No significant calcification presented in 
all sites of anastomosis. After each anastomosis, the blood, air and debris, were flushed out. Intravenous infusion of ephedrine ( $4 \mathrm{mg}$, 4 times) and phenylephrine $(0.1 \mathrm{mg}$, two times) were used for management of transient hypotension after declamping and reperfusion. Total clamping time, i.e., ischemic time of the left leg, was 111 minutes. Total operative time was 245 minutes and total time of anesthesia was 300 minutes. Total Operative course was uneventful, and pulsation of bilateral femoral and dorsal artery was normal.

Just after the extubation, he complained of severe pain of his left lower limb. Pale color and coldness of the left leg were obvious. Duplex ultrasound demonstrated normal arterial flow of the left femoral and popliteal artery. Both posterior tibial and dorsalis pedis pulses of the left foot were also detected by Doppler ultrasound. There was no change in color of the toes. For pain control, fentanyl infusion was started and it relieved the pain. Three hours after the operation, he again complained of his left lower limb pain. Laboratory data showed increased transaminase (aspartate transaminase $363 \mathrm{mg} / \mathrm{dl}$, alanine transaminase 99mg/ dl) and creatine kinase $(36273 \mathrm{mg} / \mathrm{dl})$. Contrast computed tomography (CT) demonstrated normal vasculature of the anterior tibial, posterior tibial and peronial arteries, however, significant swelling of the soleus muscle was found (Figure 1). Infusion of heparin and prostaglandin E1 were started. Twelve hours after the operation, edema of the left lower leg had severely progressed, and immediate fasciotomy was performed to relieve compartment syndrome. Discoloration of the toes of the left foot started one week after the operation and deteriorated (Figure 2). Amputation of the second, third and fourth toes was performed 4 months after the operation.

\section{Discussion}

Lower extremity ischemia may occur after graft replacement for abdominal aortic aneurysm, and this complication is caused by embolization of aortic debris, possible due to aneurysm mobilization or aortic/iliac clamping in most of those cases. "Blue toe" may result from this condition, and necessitate amputation in some cases. However, the present case did not show any sign of embolic event, such as blue toes, loss of arterial pulsation or loss of Doppler flow, after the operation. Normal arterial perfusion of the lower limb was confirmed by postoperative CT.

Unfortunately, we could not present clear explanation regarding how the compartment syndrome occurred after Y graft replacement with vascular clamping time less than 2 hours. Although there is no clear evidence for the mechanism, diffuse peripheral vasospasm could have associated with the pathophysiology. Previous case reports of vasospasm induced by ergotamine [1] or intra-arterial infusion of diazepam [2] have similarities of the present case in severity and rapid progression of tissue damage. Preoperative episodes of leg pain might have associated with lower leg vasospasm. There are many possibilities which induced vasospasm during the operation, such as sympathetic nerve responses by vascular manouver, or adrenergic agonist. Phenylephrine is apha 1-adrenergic agnonist, and ephedrine is a mixed adrenergic agonist which stimulates both apha- and beta- adrenergic receptors, and both increase peripheral resistance by inhibition of endothelium-dependent vasodilation $[3,4]$. This pharmacological mechanism might have caused severe extensive vasospasm in the left lower limb. If so, prompt intravenous use of calcium channel blocker, like nifedipine, should have relieved the symptoms and salvaged the toes. However, there luck the clinical information to support this theory, and the pathophysiological mechanism remains unclear.

\section{References}

1. Demir S, Akin S, Tercan F, Aribogan A, Oguzkurt L (2010) Ergotamineinduced lower extremity arterial vasospasm presenting as acute limb ischemia. Diagn Interv Radiol 16(2): 165-167.

2. Joist A, Tibesku CO, Neuber M, Freichmann U, Joosten U (1999) Gangrene of the fingers caused by accidental intraarterial injection of diazepam. Dtsch Med Wochenschr 124(24): 755-758.

3. Dillon PF, Root-Bernstein RS, Lieder CM (2004) Antioxidantindependent ascorbate enhancement of cathecholamine-induced contractions of vascular smooth muscle. Am J Physiol Heart Circ Physiol 286(6): H2353-H2360.

4. Ives SJ, Fadel PJ, Brothers RM, Sander M, Wray DW (2014) Exploring the vascular smooth muscle receptor landscape in vivo: ultrasound Doppler versus near-infrared spectroscopy assessments. Am J Physiol Heart Circ Physiol 306(5): H771-H776.

\section{This work is licensed under Creative} Commons Attribution 4.0 License DOI: $10.19080 /$ JOCCT.2017.06.555694

\section{Your next submission with Juniper Publishers} will reach you the below assets

- Quality Editorial service

- Swift Peer Review

- Reprints availability

- E-prints Service

- Manuscript Podcast for convenient understanding

- Global attainment for your research

- Manuscript accessibility in different formats ( Pdf, E-pub, Full Text, Audio)

- Unceasing customer service

Track the below URL for one-step submission https://juniperpublishers.com/online-submission.php 